\title{
Development and Validation of a Simultaneous Bioanalytical Method for Methotrexate, Sulfasalazine and Hydroxychloroquine in Rat Plasma following Single Step Protein Precipitation Technique
}

\author{
Pichili Ajitha Reddy, Amit Kumar Sahu, Manish Kumar Sharma, Pinaki Sengupta* \\ Department of Pharmaceutical Analysis, National Institute of Pharmaceutical Education and Research (NIPER), \\ Ahmedabad, Gujarat, INDIA
}

\begin{abstract}
Background: Triple therapy of methotrexate, sulfasalazine and hydroxychloroquine is widely used in the treatment of rheumatoid arthritis. Different studies reported the superior efficacy of combination of these three drugs in the improvement of this disease state. However, there is still a lot of scopes remains for preclinical study of this combination in future. Establishment of bioanalytical method is essential for quantitating these analytes in the samples from such types of studies. Therefore, in this study, we aim to develop a simultaneous method for quantification of methotrexate, sulfasalazine and hydroxychloroquine in rat plasma through a single run. Materials and Methods: The method includes a simple single step protein precipitation technique for extraction of all the three analytes from rat plasma with more than $84 \%$ recovery. The method was validated according to the USFDA guideline for a calibration range of $0.50-10 \mu \mathrm{g} / \mathrm{mL}$. Results: Overall, the method showed acceptable accuracy (92.14-116.12\%) and precision (\%coefficient of variation; 0.79-11.94\%) at lower limit of quantification and three quality control levels. Analytes were found to be stable in all the tested stability study conditions. Conclusion: We have established a simultaneous bioanalytical method for methotrexate, sulfasalazine and hydroxychloroquine in rat plasma. Applicability of the method has been established through an oral pharmacokinetic study of the combination in rat.

Key words: Methotrexate, Sulfasalazine, Hydroxychloroquine, Bioanalytical method development and validation, Pharmacokinetic application.
\end{abstract}

\section{INTRODUCTION}

Rheumatoid Arthritis (RA), a chronic autoimmune disorder that mainly attacks the synovial tissue of the joints and if left untreated, leads to substantial mortality and morbidity. ${ }^{1}$ premature death, and socioeconomic burdens. A better understanding of how the pathological mechanisms drive the deterioration of RA progress in individuals is urgently required in order to develop therapies that will effectively treat patients at each stage of the disease progress. Here we dissect the etiology and pathology at specific stages. The symptoms and progression of RA can be controlled by treatment strategies, which include non-steroidal anti-inflammatory drugs (relives from pain and stiffness), corticosteroids (minimize the inflammatory events) and Disease-Modifying Antirheumatic Drugs (DMARDs) (suppress progression of RA). ${ }^{2-4}$ However, rheumatologists preferred to prescribe combination therapy rather than mono-therapy because of the increased efficacy and enhanced improvement of the patient over time. ${ }^{5}$ Dell et al. performed a two years study and measured the difference in the improvement of patients with three different treatments i.e, Methotrexate (MXT) alone, Sulfasalazine (SFS) and Hydroxychloroquine (HCQ) combined
Submission Date: 11-10-2019; Revision Date: 27-02-2020; Accepted Date: 14-04-2020

DOI: 10.5530/ijper.54.2s.94 Correspondence: Dr. Pinaki Sengupta Department of Pharmaceutical Analysis, National Institute of Pharmaceutical Education and Research-Ahmedabad, Gandhinagar-382355, Gujarat, INDIA.

Phone: +91-7966745555 E-mail: psg725@gmail.com

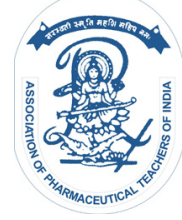

www.ijper.org 
treatment and combination of all three. The combined treatment of MXT, SFS and HCQ, called triple therapy is found to be an effective treatment that increases efficacy without an increase in the toxicity when compared to gold standard treatment of MXT alone..$^{6-9}$ After two years, it was observed that improvement of symptoms was 33\% for patients on MXT treatment and $77 \%$ with least side effects for patients receiving a combination of all three drugs. The same research group reported a study on the combined treatment of MXT and SFS, MXT and HCQ and combination of all three drugs and observed the higher efficacy of the three-drug combination compared to the other two combinations. ${ }^{8}$ The effectiveness of combined treatment of these three drugs was investigated by two other groups and found that it was more effective in achieving improvement in the disease condition, Furthermore, the study revealed that the subjects given the triple therapy were less susceptible to $\mathrm{C} 1-\mathrm{C} 2$ subluxation (responsible for impairment in rotation of the neck) ${ }^{8,10}$ From the above studies, it can be concluded that combination of these three drugs provides higher efficacy in remission of such disease state.

There is some literature published recommending optimization of MXT treatment for patients with rheumatoid arthritis. ${ }^{11}$ Similar optimization may be required for the other two drugs SFS and HCQ when given in combination. In addition, there is a need to understand the pharmacokinetic interaction between MXT, SFS and HCQ for improving the therapeutic profile of this triple combination therapy. Requirement of any dose adjustment can also be evaluated through preclinical pharmacokinetic study of the combination. Therefore, there is still a lot of scope for preclinical study for this combination, which is expected to be performed in future. Establishment of bioanalytical method is essential for quantitating these analytes in the samples from such types of studies. There are several reported bioanalytical methods for quantification of MXT, ${ }^{12-15}$ SFS $^{16,17}$ and HCQ ${ }^{18,19}$ either alone or in combination with other drugs and metabolites. However, until today, no method has been reported to simultaneously estimate MXT, SFS and HCQ not only in plasma but also in any type of biological matrices. The present study aims to establish a sensitive high-performance liquid chromatography (HPLC) method of bioanalysis to estimate simultaneously MXT, SFS and HCQ in rat plasma.

To confirm the reliability of the extraction and quantitation method developed for bioanalysis of analytes, validation of the whole process is considered to be a primary requirement before applying it to ana- lyze real samples. Validation is required to be carried out to ensure the applicability of the method for its intended purpose. Although some variation is expected, it should be within a specified limit and the method should meet all the acceptance criteria of bioanalytical method validation parameters ensuring the reliability of results it generates. Therefore, this study also extended to validate the developed simultaneous quantitation method of MXT, SFS and HCQ following the suitable regulatory guidelines.

\section{MATERIALS AND METHODS}

\section{Chemicals and Reagents}

MXT (Figure 1A), SFS (Figure 1B) and HCQ (Figure 1C) were purchased from Sigma Aldrich. Each and every solvents and buffer required for development, validation and analysis of samples for this research were of HPLC grade and procured from Fisher scientific. The intended quality of water was generated through a Millipore water purification system.

\section{Instruments}

The HPLC system equipped with 1260 quaternary pump (DEADP18979), 1260 autosampler (DEADA00334) and 1260 DAD VL detector (DEAAX08589) of Agilent Technology (Germany) was employed. The centrifuge system of Thermo Scientific, USA and vortex shaker of IKA, USA was used in different stages of sample preparations. The $\mathrm{pH}$ meter used for adjustment of mobile phase $\mathrm{pH}$ was of Eutech Instruments, India.

[A]

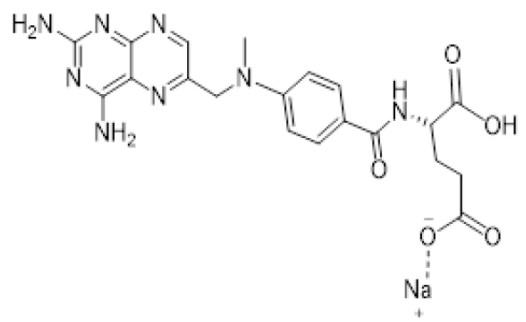

[B]
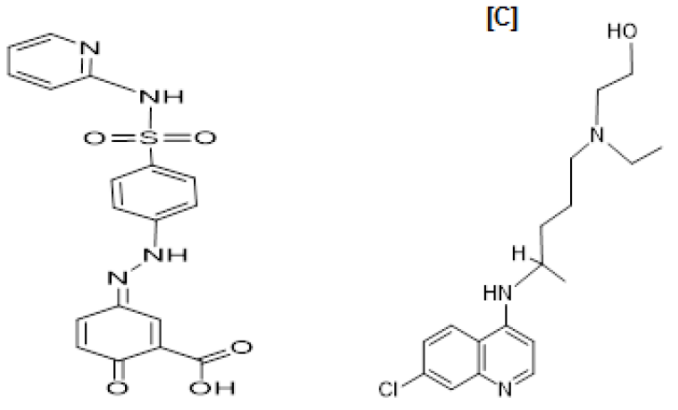

Figure 1: Molecular structure of [A] Methotrexate, [B] Sulfasalazine and [C] Hydroxychloroquine. 


\section{Standard Solutions, Calibration and Quality Control Samples}

Individual standard solution was prepared by dissolving $10 \mathrm{mg}$ each of MXT, SFS and HCQ in $10 \mathrm{~mL}$ of a mixed solvent composed of acetonitrile and water (50:50) to obtain $1 \mathrm{mg} / \mathrm{mL}$ concentration. The mixed working calibration standard solutions $(5,10,20,40,60,80$ and $100 \mu \mathrm{g} / \mathrm{mL}$ ) were prepared taking appropriate quantity of the individual standard solution and diluting accordingly with the same diluent. Final calibration solutions were prepared by spiking a $10 \mu \mathrm{L}$ aliquot of mixed working solution to the $90 \mu \mathrm{L}$ of blank rat plasma. The mixed quality control (QC) samples were prepared at three concentration levels of $1.5 \mu \mathrm{g} / \mathrm{mL}$ (low-quality control, LQC), $5 \mu \mathrm{g} / \mathrm{mL}$ (medium-quality control, MQC) and $9 \mu \mathrm{g} / \mathrm{mL}$ (high-quality control, HQC). Solutions were kept at $2-8^{\circ} \mathrm{C}$ until further use.

\section{Sample Preparation}

The drugs were extracted from the plasma samples by protein precipitation method. To the $90 \mu \mathrm{L}$ of blank rat plasma, $10 \mu \mathrm{L}$ of the working solution of drug mixture was added and vortex mixed for $30 \mathrm{sec}$. Thereafter, $300 \mu \mathrm{L}$ of acetonitrile containing $50 \mu \mathrm{g} / \mathrm{mL}$ of IS was added and vortexed for $30 \mathrm{sec}$. The prepared sample was subjected to centrifugation at $8000 \mathrm{~g}$ for 10 min at $4^{\circ} \mathrm{C}$. Finally, $250 \mu \mathrm{L}$ of the supernatant was taken out and used for HPLC analysis.

\section{Chromatographic Conditions}

Eclipse $C_{18}(250 \mathrm{~mm}$ X $4.6 \mathrm{~mm}), 5 \mu \mathrm{m}$ particle size column having a porosity of $100 \AA$ was found to be the best stationary phase in the HPLC analysis. The mobile phase employed for the analysis was $10 \mathrm{mM}$ ammonium acetate buffer ( $\mathrm{pH}$ 5.5) as the aqueous phase and acetonitrile as an organic phase with a flow rate of $1 \mathrm{~mL} /$ min. The UV-visible variable wavelength detector was used to detect the analytes at a common wavelength of $308 \mathrm{~nm}$. The mobile phase composition in the gradient elution mode for the organic phase was varied from $10 \%$ to $90 \%$. The optimized gradient program consisted of the acetonitrile composition of 10\% in 0-2 $\mathrm{min}$, then increased to $30 \%$ in $2-4 \mathrm{~min}$, kept constant at 30\% from 4-8min, increased to $90 \%$ in $8-14$ min, kept constant at $90 \%$ in 14-16 min, decreased to $10 \%$ from $16-18 \mathrm{~min}$ and finally kept constant for re-equilibrating the column from 18-20 min Apremilast was used as an internal standard (IS) because of its good chromatographic response.. The retention time of MXT, SFS, HCQ and IS was about $6.4 \mathrm{~min}, 7.0 \mathrm{~min}$, $8.9 \mathrm{~min}$ and $14.6 \mathrm{~min}$, respectively over a total run time of $20 \mathrm{~min}$.

\section{Bioanalytical Method Validation}

The developed bioanalytical method to simultaneously quantify MXT, SFS and HCQ was validated as per the United States Food and Drug Administration (USFDA) bioanalytical method validation guideline. ${ }^{20}$ The validation parameters tested were specificity, linearity, accuracy, precision, recovery, matrix effect and stability. ${ }^{20-22}$

\section{Selectivity}

Selectivity was evaluated to confirm that the method is correctly targeting the desired analytes to quantify. Standard blank plasma samples of different sources were screened for establishing the specificity of the method. Blank rat plasma was collected from six separate rats. All the blank samples were analyzed to check for any possible interference and selectivity was evaluated at the lower limit of quantification (LLOQ). The acceptance criteria for selectivity of the analytical procedure was set so that the area response at the retention time of individual analyte in blank should be $\leq 20 \%$ compared to the response in LLOQ. ${ }^{20}$

\section{Carryover}

Impact of carryover from the previous injection to the subsequent injection on the accuracy for the analytes was determined by injecting blank samples after HQC injection. According to the USFDA guideline, carryover should not exceed $20 \%$ of LLOQ. ${ }^{20}$

\section{Sensitivity}

Sensitivity of the bioanalytical methodology was determined after injecting the lowest nonzero standard on the calibration curve (LLOQ) six times. According to the USFDA guideline, the area of the peaks of the analytes at LLOQ should be $>5$ times the area of blank at the same retention time. The accuracy should be within $\pm 20 \%$ of theoretical concentration and the precision should be $\pm 20 \%$ of Coefficient of Variation $(\mathrm{CV}) .^{20}$

\section{Linearity}

The correlation between the known concentration and response was evaluated through a regression analysis of calibration curve constructed using a seven-point $(0.5,1,2,4,6,8$ and $10 \mu \mathrm{g} / \mathrm{mL})$ standard calibration curve. Calibration curve was constructed with drug/IS ratio on $\mathrm{Y}$-axis and concentration on $\mathrm{X}$-axis and correlation coefficient $\left(R^{2}\right)$ values were calculated.

\section{Accuracy}

Adjacency of the average estimated values determined by the developed bioanalytical method to that of the 
true values of the analytes was measured by repeated sample analysis of different concentrations. The accuracy was estimated at LLOQ, LQC, MQC and HQC levels in six replicates. Ratio of drug/IS area was considered in linearity line equation $(y=m x+c)$ to get the concentration of the given sample. The deviation of the average from the theoretical value served as the estimation of accuracy. Acceptance limit for average value was $\pm 15 \%$ of the theoretical concentration except at LLOQ, where it should be within $\pm 20 \%$. $^{20,23}$

\section{Precision}

Adjacency of the individual measured value of the analyte among numerous aliquots of uniform volume of the plasma was assessed by injecting six replicates at LLOQ, LQC, MQC and HQC levels. The precision of the HPLC-UV method was evaluated by determining the $\% \mathrm{CV}$ of the repeated injections. Intraday precision was evaluated by determining $\% \mathrm{CV}$ of the response of the repeated injections injected on the same day. On the other hand, interday precision was calculated after comparison of the measured values of the samples injected on three different days. According to the USFDA guideline, the precision determined at each concentration level should not exceed $15 \%$ of the CV except for the LLOQ, where it should be $\pm 20 \%{ }^{20,23}$

\section{Recovery and Matrix Effect}

Recovery study was performed through the comparison of the chromatographic response for extracted samples at LQC, MQC and HQC with unextracted samples in three replicates which correspond $100 \%$ recovery. Matrix effect was assessed after a comparison of the response in the pre-spiked sample to the response in neat samples. ${ }^{23-25}$

\section{Stability}

The stability of the compound for a specified time period was assessed under different specified conditions in several ways. All the stability studies were carried out at two concentration levels of LQC and HQC. Three replicates at each concentration were assessed. The stock solution stability study procedure included an evaluation of the stability of the compounds in their combined stock solution of $100 \mu \mathrm{g} / \mathrm{mL}$. Stock solution stability of spiked QC samples was evaluated by preparing samples from the stock solution that was prepared before 7 days. Benchtop stability analysis was carried out by analyzing the plasma samples spiked with the analytes after keeping $8 \mathrm{hr}$ at room temperature. Autosampler stability of the analytes in the processed sample was determined by injecting the samples after keeping $12 \mathrm{hr}$ inside the autosampler maintained at $15^{\circ} \mathrm{C}$. Stability of the analytes in the samples of third freeze-thaw cycles was assessed by freezing at $-80^{\circ} \mathrm{C}$ and after automatic thawing when kept at normal laboratory conditions. Short term stability of the analyte in the spiked plasma samples was carried out by storing the samples inside freezer at $-80^{\circ} \mathrm{C}$ and analyzing after 7 days. As per the USFDA guideline, in stability study, the accuracy ( $\%$ nominal) at each level should be within $\pm 15 \% .^{20,26}$

\section{Pharmacokinetic Study}

A single dose oral pharmacokinetic study of MXT, SFS and HCQ after their combination treatment in rat was performed to understand the applicability of the developed method. The animal experiment protocol (approval no\# NIPERA/IAEC/2018/057) was approved by the Institutional Animal Ethics Committee before commencing the study.

\section{Study Design}

Pharmacokinetics study was performed in male Sprague Dawley rats. The rats were brought from Zydus Research Centre, Ahmedabad, India. Average weight of the rats was 220-250g. A total number of 10 animals were divided equally into two groups (control and treatment) and placed in two separate cages. Animals were assigned for the experiment before one week of dosing. The animals were housed in an air conditioning unit with air exhaust having a relative humidity of $60 \pm 5 \%$ and a temperature of $25 \pm 3^{\circ} \mathrm{C}$. The rats were exposed to a 10/14hr light/dark cycle. Amrut certified rodent diet was given (Maharashtra Chakan Oil Mill Ltd.).

The dose administered to the rats based on their body weight. The dose of MXT, SFS and HCQ was $2.5 \mathrm{mg} / \mathrm{kg}$, $154 \mathrm{mg} / \mathrm{kg}$ and $54 \mathrm{mg} / \mathrm{kg}$, respectively. Approximately $300 \mu \mathrm{L}$ of blood sample was collected at $0 \mathrm{hr}$ (pre-dose) and then at $30 \mathrm{~min}, 1 \mathrm{hr}, 2 \mathrm{hr}, 4 \mathrm{hr}, 5 \mathrm{hr}, 6 \mathrm{hr}, 10 \mathrm{hr}, 24 \mathrm{hr}$ and $36 \mathrm{hr}$ post-dose from each animal. Retro-orbital route was used to withdraw the blood from the rats and transferred into the $1.5 \mathrm{~mL}$ microcentrifuge tubes having anticoagulant in it. Plasma was separated by centrifugation at $10000 \mathrm{rpm}$ for $10 \mathrm{~min}$ at $4^{\circ} \mathrm{C}$ and stored at $-80^{\circ} \mathrm{C}$ until analysis. The samples were subjected to quantitative analysis using the developed bioanalytical method.

\section{Data Analysis}

The maximum plasma concentration $\left(\mathrm{C}_{\max }\right)$ and the time taken to reach the same $\left(\mathrm{t}_{\max }\right)$ were determined from the plasma concentration profile. The area under the curve upto last measurable time $\left(\mathrm{AUC}_{0-\mathrm{t}}\right)$ was deter- 
mined following linear trapezoidal rule by summing the area from 0 to the last detectable time points. Elimination rate constant $\left(\mathrm{k}_{\mathrm{e}}\right)$ was obtained from the slope of the linearity curve constructed with the points after the $\mathrm{C}_{\max }$. Elimination half-life $\left(\mathrm{t}_{1 / 2}\right)$ was calculated from the formula $0.693 / \mathrm{k}_{\mathrm{el}}$. The area under the curve to infinity time $\left(\mathrm{AUC}_{0-\infty}\right)$ was determined by adding $\mathrm{AUC}_{0-\mathrm{t}}$ with last measurable concentration divided by $\mathrm{k}_{\mathrm{el}}{ }^{27}$

\section{RESULTS AND DISCUSSION}

\section{Selectivity}

No significant interferences of any plasma components were observed in the HPLC chromatogram at the retention time of MXT, SFS and HCQ. In actual, the response of the analytes in blank samples was zero. Therefore, it can be stated that peak area at the retention time in blank samples was $\leq 20 \%$ compared to the area in LLOQ for all the three analytes meeting the acceptance criteria for the selectivity of the method. Representative chromatograms for absolute blank (without IS), blank with IS, LLOQ and plasma samples have been shown in Figure 2A,2B,2C,2D, respectively.
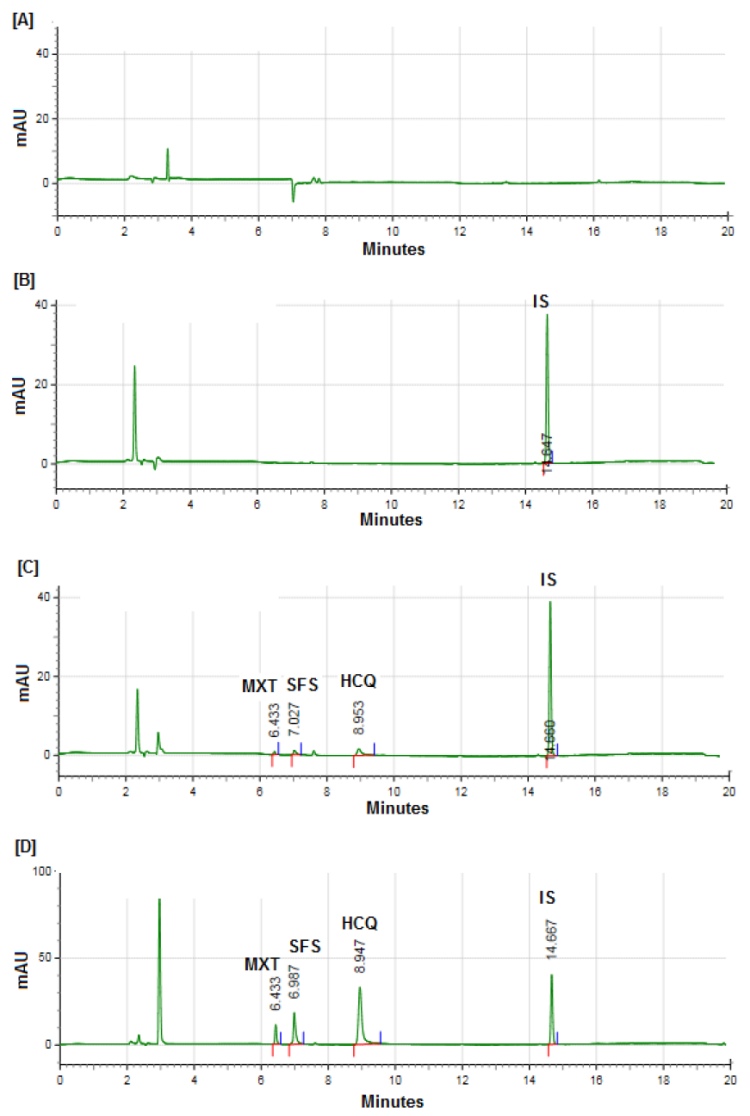

Figure 2: Representative chromatograms for [A] absolute blank (without IS), [B] blank with IS, [C] LLOQ and [D] plasma samples.

\section{Carryover}

No chromatographic response of either MXT, SFS or HCQ was observed at their corresponding retention time in blank injection injected after HQC samples. Therefore, the method can be stated as devoid of any carryover for the analytes.

\section{Sensitivity}

In the sensitivity test, the analyte response for MXT, SFS and HCQ at the LLOQ was $>5$ times the analyte response observed in the blank sample. The mean accuracy for MXT, SFS and HCQ for the six LLOQ injections was $88.80 \%, 108.00 \%$ and $100.33 \%$, respectively. The corresponding precision $(\% \mathrm{CV})$ values for MXT, SFS and HCQ were $7.77 \%, 5.62 \%$ and $1.50 \%$, respectively. Therefore, the method can be considered as sensitive enough to detect all three analytes simultaneously at their individual LLOQ level of $0.5 \mu \mathrm{g} / \mathrm{mL}$.

\section{Linearity}

The linearity of the method was evaluated through regression analysis of calibration curve constructed using a seven-point standard solution. The $R^{2}$ value for MXT, SFS and HCQ was greater than 0.996, 0.997 and 0.995 , respectively. Accuracy of the back-calculated concentration of the calibration points ranged from 94.33-112.95\% for MXT, 95.96-114.32\% for SFS and 96.34-110.31\% for HCQ. The corresponding precision $(\% \mathrm{CV})$ values ranged from $0.78-13.59 \%, 0.99-9.13 \%$ and $0.20-5.45 \%$ for MXT, SFS and HCQ, respectively. Therefore, the method showed consistent results for all the calibration points and thus, can be considered to be linear over the calibration range of $0.50-10 \mu \mathrm{g} / \mathrm{mL}$ for all the three analytes.

\section{Accuracy}

Accuracy of the back-calculated concentrations of QC samples including LLOQ for six replicates was in the range of $92.14-107.04 \%, 93.01-116.12 \%$ and $96.50-111.79 \%$ for MXT, SFS and HCQ, respectively. Accuracy values were found to be within the acceptance limit of $\pm 15 \%$ for QC samples (LQC, MQC and HQC) and $\pm 20 \%$ for LLOQ. The results of accuracy study for MXT, SFS and HCQ have been summarized in Table 1-3, respectively.

\section{Precision}

In intraday precision study, $\% \mathrm{CV}$ of back-calculated concentrations for all quality control samples for the six replicates were $2.30-11.82 \%, 1.44-11.94 \%$ and $0.79-11.09 \%$, respectively. The $\% \mathrm{CV}$ of back-calculated concentrations for all QC samples of the different batches of three different days (interday precision) 


\begin{tabular}{|c|c|c|c|c|c|}
\hline \multicolumn{6}{|c|}{ Intra-day } \\
\hline $\begin{array}{l}\text { Quality } \\
\text { control }\end{array}$ & Run & $\begin{array}{c}\text { Mean } \\
(\mu \mathrm{g} / \mathrm{mL})\end{array}$ & SD & $\% \mathrm{CV}$ & $\begin{array}{c}\% \\
\text { Accuracy }\end{array}$ \\
\hline \multirow[t]{3}{*}{ LLOQ } & 1 & 0.52 & 0.01 & 2.65 & 104.76 \\
\hline & 2 & 0.47 & 0.02 & 5.10 & 93.31 \\
\hline & 3 & 0.46 & 0.01 & 2.30 & 92.14 \\
\hline \multirow[t]{3}{*}{ LQC } & 1 & 1.39 & 0.07 & 4.79 & 92.43 \\
\hline & 2 & 1.43 & 0.17 & 11.69 & 95.63 \\
\hline & 3 & 1.39 & 0.08 & 5.80 & 92.83 \\
\hline \multirow[t]{3}{*}{ MQC } & 1 & 5.15 & 0.32 & 6.14 & 103.06 \\
\hline & 2 & 5.05 & 0.37 & 7.23 & 101.19 \\
\hline & 3 & 5.35 & 0.63 & 11.82 & 107.04 \\
\hline \multirow[t]{3}{*}{ HQC } & 1 & 9.32 & 0.23 & 2.48 & 103.52 \\
\hline & 2 & 9.33 & 0.39 & 4.23 & 103.63 \\
\hline & 3 & 8.91 & 0.24 & 2.68 & 99.04 \\
\hline \multicolumn{6}{|c|}{ Inter-day } \\
\hline \multicolumn{2}{|c|}{ LLOQ } & 0.48 & 0.03 & 6.90 & 96.74 \\
\hline \multicolumn{2}{|c|}{ LQC } & 1.40 & 0.11 & 7.79 & 93.63 \\
\hline \multicolumn{2}{|c|}{ MQC } & 5.19 & 0.45 & 8.67 & 103.76 \\
\hline \multicolumn{2}{|c|}{ HQC } & 9.19 & 0.34 & 3.73 & 102.06 \\
\hline
\end{tabular}

\begin{tabular}{|c|c|c|c|c|c|}
\hline \multicolumn{6}{|c|}{ Intra-day } \\
\hline $\begin{array}{c}\text { Quality } \\
\text { controls }\end{array}$ & Runs & $\begin{array}{c}\text { Mean } \\
\text { found } \\
\text { ( } \mu \mathrm{g} / \mathrm{mL})\end{array}$ & SD & $\% \mathrm{CV}$ & $\begin{array}{c}\% \\
\text { Accuracy }\end{array}$ \\
\hline \multirow[t]{3}{*}{ LLOQ } & 1 & 0.58 & 0.01 & 1.44 & 116.12 \\
\hline & 2 & 0.51 & 0.02 & 3.65 & 102.68 \\
\hline & 3 & 0.55 & 0.03 & 5.91 & 109.15 \\
\hline \multirow[t]{3}{*}{ LQC } & 1 & 1.40 & 0.10 & 7.29 & 93.01 \\
\hline & 2 & 1.50 & 0.18 & 11.94 & 99.72 \\
\hline & 3 & 1.60 & 0.04 & 2.65 & 106.70 \\
\hline \multirow[t]{3}{*}{ MQC } & 1 & 5.05 & 0.51 & 10.09 & 100.98 \\
\hline & 2 & 4.86 & 0.25 & 5.15 & 97.17 \\
\hline & 3 & 4.97 & 0.50 & 10.03 & 99.32 \\
\hline \multirow[t]{3}{*}{ HQC } & 1 & 9.76 & 0.39 & 3.96 & 108.48 \\
\hline & 2 & 9.10 & 0.31 & 3.42 & 101.16 \\
\hline & 3 & 9.14 & 0.29 & 3.16 & 101.52 \\
\hline \multicolumn{6}{|c|}{ Inter-day } \\
\hline \multicolumn{2}{|c|}{ LLOQ } & 0.55 & 0.04 & 6.41 & 109.32 \\
\hline \multicolumn{2}{|c|}{ LQC } & 1.50 & 0.14 & 9.54 & 99.81 \\
\hline \multicolumn{2}{|c|}{ MQC } & 4.96 & 0.42 & 8.42 & 99.15 \\
\hline \multicolumn{2}{|c|}{ HQC } & 9.33 & 0.44 & 4.72 & 103.72 \\
\hline
\end{tabular}

\begin{tabular}{|c|c|c|c|c|c|}
\hline \multicolumn{6}{|c|}{ Intra-day } \\
\hline $\begin{array}{l}\text { Quality } \\
\text { controls }\end{array}$ & Runs & $\begin{array}{l}\text { Mean found } \\
(\mu \mathrm{g} / \mathrm{mL})\end{array}$ & SD & $\% \mathrm{CV}$ & $\begin{array}{c}\% \\
\text { Accuracy }\end{array}$ \\
\hline \multirow[t]{3}{*}{ LLOQ } & 1 & 0.49 & 0.01 & 2.61 & 97.94 \\
\hline & 2 & 0.56 & 0.00 & 0.79 & 111.79 \\
\hline & 3 & 0.51 & 0.01 & 1.01 & 101.36 \\
\hline \multirow[t]{3}{*}{ LQC } & 1 & 1.61 & 0.06 & 3.53 & 107.29 \\
\hline & 2 & 1.61 & 0.09 & 5.64 & 107.41 \\
\hline & 3 & 1.64 & 0.06 & 3.40 & 109.24 \\
\hline \multirow[t]{3}{*}{ MQC } & 1 & 4.95 & 0.53 & 10.77 & 99.06 \\
\hline & 2 & 4.89 & 0.41 & 8.46 & 97.77 \\
\hline & 3 & 4.82 & 0.53 & 11.09 & 96.50 \\
\hline \multirow[t]{3}{*}{ HQC } & 1 & 9.13 & 0.45 & 4.95 & 101.48 \\
\hline & 2 & 8.98 & 0.36 & 4.00 & 99.74 \\
\hline & 3 & 8.85 & 0.43 & 4.88 & 98.34 \\
\hline \multicolumn{6}{|c|}{ Inter-day } \\
\hline \multicolumn{2}{|c|}{ LLOQ } & 0.52 & 0.03 & 6.04 & 103.70 \\
\hline \multicolumn{2}{|c|}{ LQC } & 1.62 & 0.07 & 4.13 & 107.98 \\
\hline \multicolumn{2}{|c|}{ MQC } & 4.89 & 0.47 & 9.62 & 97.78 \\
\hline \multicolumn{2}{|c|}{ HQC } & 8.99 & 0.41 & 4.55 & 99.85 \\
\hline
\end{tabular}

were in the range of $3.73-9.90 \%, 4.72-9.54 \%$ and 4.13 $9.62 \%$ for MXT, SFS and HCQ, respectively. The precision study confirms the repeatability of the method as all the calculated values met the acceptance criteria of $\% \mathrm{CV}$ which varied within $\pm 15 \%$ for QC samples and $\pm 20 \%$ for LLOQ. The accuracy and precision results obtained in the method validation experiment for MXT, SFS and HCQ have been summarized in Table 1-3, respectively.

\section{Recovery and Matrix Effect}

Average recovery for MXT, SFS and HCQ at the three QC levels were $85.51 \%, 91.26 \%$ and $84.22 \%$, respectively. The matrix effect at the same three concentration levels was found to be $4.20 \%, 3.43 \%$ and $8.41 \%$, respectively. Therefore, the sample preparation method showed to have good extraction efficiency for all three analytes from the rat plasma samples.

\section{Stability}

In the stability experiment, the accuracy ( $\%$ nominal) for each individual run of three replicates at two concentration levels varied within $\pm 15 \%$ for all the three analytes. The mean accuracy for MXT, SFS and HCQ was ranged from 88.86-96.41\%, 85.81-108.78\% and $85.98-98.80 \%$, respectively. Therefore, all three analytes can be considered to be stable in all tested stability 


\begin{tabular}{|c|c|c|c|c|c|c|c|c|c|c|}
\hline \multirow{2}{*}{$\begin{array}{l}\text { Stability } \\
\text { study }\end{array}$} & \multirow[b]{2}{*}{ QC } & \multicolumn{3}{|c|}{ MXT } & \multicolumn{3}{|c|}{ SFS } & \multicolumn{3}{|c|}{ HCQ } \\
\hline & & $\begin{array}{c}\text { Mean } \\
(\mu \mathrm{g} / \mathrm{mL})+\mathrm{SD}\end{array}$ & $\begin{array}{l}\text { CV } \\
(\%)\end{array}$ & $\begin{array}{c}\text { Accuracy } \\
(\%)\end{array}$ & $\begin{array}{c}\text { Mean } \\
(\mu \mathrm{g} / \mathrm{mL})+\mathrm{SD}\end{array}$ & $\begin{array}{l}\text { CV } \\
(\%)\end{array}$ & $\begin{array}{c}\text { Accuracy } \\
(\%)\end{array}$ & $\begin{array}{c}\text { Mean } \\
(\mu \mathrm{g} / \mathrm{mL})+\mathrm{SD}\end{array}$ & $\begin{array}{l}\text { CV } \\
(\%)\end{array}$ & $\begin{array}{c}\text { Accuracy } \\
(\%)\end{array}$ \\
\hline \multirow{2}{*}{$\begin{array}{l}\text { Stock solution } \\
\text { (7days) }\end{array}$} & LQC & $1.45+0.03$ & 2.11 & 96.41 & $1.43+0.03$ & 2.13 & 95.63 & $1.47+0.04$ & 2.99 & 97.85 \\
\hline & HQC & $8.59+0.30$ & 3.53 & 95.40 & $8.75+0.33$ & 3.79 & 97.26 & $8.77+0.45$ & 5.17 & 97.41 \\
\hline \multirow{2}{*}{ Benchtop (8h) } & LQC & $1.33+0.08$ & 6.02 & 88.86 & $1.37+0.06$ & 4.58 & 91.39 & $1.43+0.07$ & 4.73 & 95.07 \\
\hline & HQC & $8.30+0.53$ & 6.43 & 92.18 & $8.96+0.43$ & 4.82 & 99.51 & $8.89+0.36$ & 4.00 & 98.80 \\
\hline \multirow{2}{*}{$\begin{array}{l}\text { Autosampler } \\
(12 \mathrm{~h})\end{array}$} & LQC & $1.36+0.04$ & 3.28 & 90.61 & $1.40+0.03$ & 1.85 & 93.10 & $1.42+0.05$ & 3.79 & 94.52 \\
\hline & HQC & $8.50+0.74$ & 8.71 & 94.48 & $9.79+0.79$ & 8.10 & 108.78 & $8.56+0.21$ & 2.41 & 95.06 \\
\hline \multirow{2}{*}{$\begin{array}{c}\text { Freeze Thaw } \\
\text { (3cycles) }\end{array}$} & LQC & $1.37+0.09$ & 6.59 & 91.01 & $1.29+0.04$ & 2.90 & 85.81 & $1.39+0.09$ & 6.51 & 92.79 \\
\hline & HQC & $8.41+0.23$ & 2.69 & 93.39 & $8.47+0.57$ & 6.75 & 94.10 & $8.64+0.74$ & 8.58 & 96.05 \\
\hline \multirow{2}{*}{$\begin{array}{l}\text { Long term } \\
\text { (7days) }\end{array}$} & LQC & $1.43+0.05$ & 3.68 & 95.41 & $1.44+0.03$ & 2.12 & 95.81 & $1.29+0.04$ & 3.38 & 86.16 \\
\hline & HQC & $8.39+0.18$ & 2.10 & 93.19 & $8.52+0.40$ & 4.68 & 94.67 & $7.74+0.28$ & 3.57 & 85.98 \\
\hline
\end{tabular}
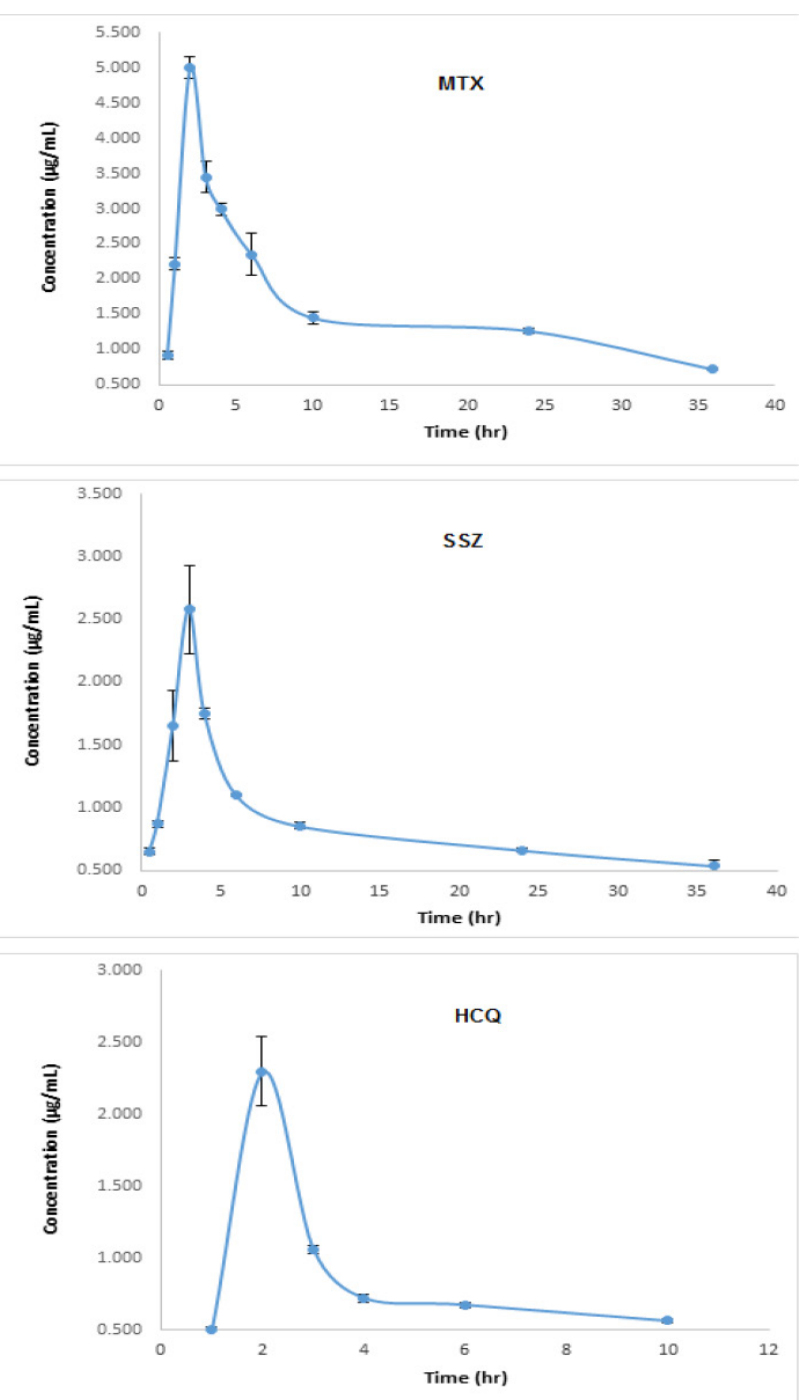

Figure 3: The plasma concentrations versus time curve for [A] Methotrexate, [B] Sulfasalazine and [C] Hydroxychloroquine. conditions of 7 days in stock solution, $8 \mathrm{hr}$ on benchtop, $12 \mathrm{hr}$ in autosampler, 3 freeze-thaw cycles and 7 days short term storage. Table 4 summarized the entire results of the stability studies observed in the method validation experiment.

\section{Pharmacokinetic Study}

The value of the major pharmacokinetic parameters of the analytes was calculated after determining their concentrations in each individual time point samples. The method was found to be suitable for analysing the plasma samples of the rat pharmacokinetic study. The $\mathrm{C}_{\max }$ values ( \pm standard deviation (SD)) for MXT, SFS and HCQ was $5.01(0.16) \mu \mathrm{g} / \mathrm{mL}, 2.58(0.39) \mu \mathrm{g} / \mathrm{mL}$ and $2.30(0.27) \mu \mathrm{g} / \mathrm{mL}$ at $2 \mathrm{hr}, 3 \mathrm{hr}$ and $2 \mathrm{hr}$, respectively. The $\mathrm{AUC}_{0-\mathrm{t}}$ values $( \pm \mathrm{SD})$ were found to be 56.04(1.91) $\mu \mathrm{g} . \mathrm{h} / \mathrm{mL}, 30.68(0.63) \mu \mathrm{g} . \mathrm{h} / \mathrm{mL}$ and $7.97(0.35) \mu \mathrm{g} . \mathrm{h} / \mathrm{mL}$ whereas, $\mathrm{AUC}_{0-\infty}$ values were $71.36(2.01) \mu \mathrm{g} \cdot \mathrm{h} / \mathrm{mL}$,

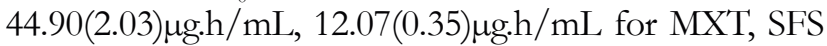
and HCQ, respectively. The $\mathrm{K}_{\mathrm{el}}$ values for MXT, SFS and HCQ were $0.05(0.00) / \mathrm{h}, 0.04(0.00) / \mathrm{hr}$ and $0.14(0.01) / \mathrm{h}$. Finally, the $t_{1 / 2}$ values for MXT, SFS and HCQ were $14.68(0.44) \mathrm{hr}, 18.23(1.19) \mathrm{h}$ and 5.04(0.41)h, respectively. The plasma concentrations versus time curve for MTX, SSZ and HCQ have been shown in Figure 3A,3B,3C, respectively.

\section{CONCLUSION}

In this study, a selective and sensitive bioanalytical HPLC method has been developed to simultaneously quantitate MXT, SFS and HCQ in rat plasma. The quantification procedure consists of a simple single step protein precipitation technique, which was capable 
to effectively extract all the analytes simultaneously from the rat plasma samples with a good recovery. Considering the complexity of bioanalysis and involvement of three analytes and an IS, the total run time of the method is less which could offer an obvious advantage of having high analysis throughput. The method can also be considered to have economic benefit in terms of minimization of the total number of analytical runs due to its capability in the quantification of MXT, SFS and HCQ simultaneously in a single run. The developed method was validated following the USFDA bioanalytical guidelines for all the validation parameters, which confirm the desired selectivity, accuracy, precision and stability of the method. The applicability of the method has been verified through a single-dose oral pharmacokinetic study of the three drugs in combination. The method is expected to be useful in all types of preclinical studies involving simultaneous quantitation of MXT, SFS and HCQ in rat plasma samples including investigation of their possible pharmacokinetic drug-drug interactions in future.

\section{ACKNOWLEDGEMENT}

We acknowledge the support of the National Institute of Pharmaceutical Education and Research-Ahmedabad for providing the necessary facilities required to carry out this research. The financial support received from the Department of Pharmaceuticals, Ministry of Chemicals and Fertilizers, Govt. of India is sincerely acknowledged.

\section{CONFLICT OF INTEREST}

The authors declare no conflict of interest.

\section{ABBREVIATIONS}

RA: Rheumatoid arthritis; DMARDs: Disease modifying antirheumatic drugs; MXT: Methotrexate; SFS: Sulfasalazine; HCQ: Hydroxychloroquine; HPLC: High performance liquid chromatography; QC: Quality control; LQC: Low quality control; MQC: Medium quality control; HQC: High quality control; IS: Internal standard; USFDA: United States Food and Drug Administration; LLOQ: Lower limit of quantification; CV: Coefficient of variation; $\mathbf{C}_{\max }$ : Maximum plasma concentration; $\mathbf{t}_{\max }$ : Time to reach maximum plasma concentration; $\mathbf{A U C}_{0-\mathrm{t}}:$ Area under the curve upto last measurable time; $\mathbf{k}_{\mathrm{el}}$ : Elimination rate constant; $\mathbf{t}_{1 / 2}$ : Elimination half-life SD: Standard deviation.

\section{REFERENCES}

1. Guo Q, Wang Y, Xu D, Nossent J, Pavlos NJ, Xu J. Rheumatoid arthritis: Pathological mechanisms and modern pharmacologic therapies. Bone Res. 2018;6(1):15.

2. Kumar P, Banik S. Pharmacotherapy Options in Rheumatoid Arthritis. Clin Med Insights Arthritis Musculoskelet Disord. 2013;6:35-43.

3. Aletaha D, Smolen JS. Diagnosis and Management of Rheumatoid Arthritis. JAMA. 2018;320(13):1360-72.

4. Kiely PD, Nikiphorou E. Management of rheumatoid arthritis. Medicine. 2018;46(4):216-21.

5. Mehta N, Schneider LK, McCardell E. Rheumatoid Arthritis: Selecting Monotherapy Versus Combination Therapy. J Clin Rheumatol Pract reports Rheum Musculoskelet Dis. 2017. doi: 10.1097/RHU.0000000000000410.

6. O'Dell JR. Combination DMARD therapy with hydroxychloroquine, sulfasalazine and methotrexate. Clin Exp Rheumatol. 1999;17:S53-8.

7. Dale J, Alcorn N, Capell H, Madhok R. Combination therapy for rheumatoid arthritis: Methotrexate and sulfasalazine together or with other DMARDs. Nat Clin Pract Rheumatol. 2007;3(8):450-8.

8. O'Dell JR, Leff R, Paulsen G, Haire C, Mallek J, Eckhoff PJ, et al. Treatment of rheumatoid arthritis with methotrexate and hydroxychloroquine, methotrexate and sulfasalazine, or a combination of the three medications: Results of a two-year, randomized, double-blind, placebo-controlled trial. Arthritis Rheum. 2002;46(5):1164-70

9. O'Dell JR, Haire CE, Erikson N, Drymalski W, Palmer W, Eckhoff PJ, et al. Treatment of rheumatoid arthritis with methotrexate alone, sulfasalazine and hydroxychloroquine, or a combination of all three medications. N Engl J Med. 1996;334(20):1287-91.

10. Neva MH, Kauppi MJ, Kautiainen H, Luukkainen R, Hannonen $P$, Leirisalo-Repo $\mathrm{M}$, et al. Combination drug therapy retards the development of rheumatoid atlantoaxial subluxations. Arthritis Rheum. 2000;43(11):2397-401.

11. Bello A, Perkins E, Jay R, Efthimiou P. Recommendations for optimizing methotrexate treatment for patients with rheumatoid arthritis. Open Access Rheumatol Res Rev. 2017;9:67-79.

12. Liu DY, Lon HK, Wang YL, DuBois DC, Almon RR, Jusko WJ. Pharmacokinetics, pharmacodynamics and toxicities of methotrexate in healthy and collagen-induced arthritic rats. Biopharm Drug Dispos. 2013;34(4):203-14.

13. Ren $X$, Wang $Z$, Yun $Y$, Meng $G$, Zhang $X$, Ding $H$, et al. Simultaneous Quantification of Methotrexate and Its Metabolite 7-Hydroxy-Methotrexate in Human Plasma for Therapeutic Drug Monitoring. Int J Anal Chem. 2019;2019:1-10.

14. Veeraraghavan S, Thappali SRS, Viswanadha S, Vakkalanka S, Rangaswamy M. Simultaneous quantification of baricitinib and methotrexate in rat plasma by LC-MS/MS: Application to a pharmacokinetic study. Sci Pharm. 2015;84(2):347-59.

15. Christianson CC, Johnson CJL, Needham SR. The advantages of microflow LC-MS/MS compared with conventional HPLC-MS/MS for the analysis of methotrexate from human plasma. Bioanalysis. 2013;5(11):1387-96.

16. Kusuhara $\mathrm{H}$, Furuie $\mathrm{H}$, Inano A, Sunagawa A, Yamada $\mathrm{S}, \mathrm{Wu} \mathrm{C}$, et al. Pharmacokinetic interaction study of sulphasalazine in healthy subjects and the impact of curcumin as an in vivo inhibitor of BCRP. Br J Pharmacol. 2012;166(6):1793-803.

17. Joseph SKSMS. Simultaneous Determination of Methotrexate and Sulfasalazine in Plasma by HPLC-DAD. Pharmaceuticals. 2015;33(2):122-38.

18. Chhonker YS, Sleightholm RL, Li J, Oupický D, Murry DJ. Simultaneous quantitation of hydroxychloroquine and its metabolites in mouse blood and tissues using LC-ESI-MS/MS: An application for pharmacokinetic studies. J Chromatogr B. 2018;1072:320-7.

19. Soichot M, Mégarbane B, Houzé P, Chevillard L, Fonsart J, Baud FJ, et al. Development, validation and clinical application of a LC-MS/MS method for the simultaneous quantification of hydroxychloroquine and its active metabolites in human whole blood. J Pharm Biomed Anal. 2014;100:131-7.

20. U.S. Department of Health and Human Services Food and Drug Administration. Guidance for Industry Bioanalytical Method Validation Guidance for Industry Bioanalytical Method Validation. Vet Med. 2018;(5). 
21. Nemani KS, Shard A, Sengupta P. Establishment of a quantitative bioanalytical method for an acetylcholinesterase inhibitor Ethyl 3-(2-(4-fluorophenyl) amino)-4-phenylthiazol-5-yl)-3-oxopropanoate including its physicochemical characterization and in vitro metabolite profiling using Liqu. J Chromatogr B. 2018;1096:214-22.

22. Biswas NM, Shard A, Patel S, Sengupta P. Drug development and bioanalytical method validation for a novel anticancer molecule, 4-(dimethylamino)-2(p-tolylamino) thiazole-5-carbonitrile. Drug Dev Res. 2018;79(8):391-9.

23. Sengupta P, Chatterjee B, Mandal UK, Gorain B, Pal TK. Development and validation of a high throughput LC-MS/MS method for simultaneous quantitation of pioglitazone and telmisartan in rat plasma and its application to a pharmacokinetic study. J Pharm Anal. 2017;7(6):381-7.
24. Reddy VK, Swamy N, Rathod R, Sengupta P. A Bioanalytical Method for Eliglustat Quantification in Rat Plasma. J Chromatogr Sci. 2019;57(7):600-705.

25. Sengupta P, Bhaumik U, Ghosh A, Sarkar AK, Chatterjee B, Bose A, et al. LC-MS-MS development and validation for simultaneous quantitation of metformin, glimepiride and pioglitazone in human plasma and its application to a bioequivalence study. Chromatographia. 2009;69(11-12):1243.

26. Sengupta P, Sarkar AK, Bhaumik U, Chatterjee B, Roy B, Chakraborty US, et al. Development and validation of an LC-ESI-MS/MS method for simultaneous quantitation of olmesartan and pioglitazone in rat plasma and its pharmacokinetic application. Biomed Chromatogr. 2010;24(12):1342-9.

27. Sengupta $P$, Chatterjee $B, P a l$ TK. Assessment of preclinical pharmacokinetics and acute toxicity of pioglitazone and telmisartan combination. Regul Toxicol Pharmacol. 2017;91:151-8.

\section{PICTORIAL ABSTRACT}

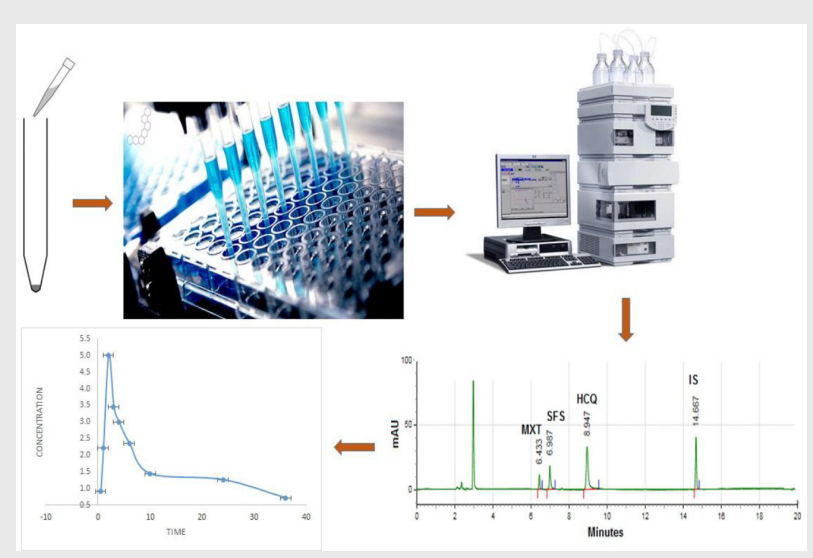

\section{SUMMARY}

We have developed and validated a simultaneous bioanalytical method for methotrexate, sulfasalazine and hydroxychloroquine in rat plasma. The method was found to be selective, sensitive, accurate, precise and stabile. Applicability of the method has been established through an oral pharmacokinetic study of the combination in rat.

\begin{abstract}
About Authors
(1)

Pichili Ajitha Reddy is a Master of Science (Graduate) in Pharmaceutical Analysis from National Institute of Pharmaceutical Education and Research (NIPER) -Ahmedabad. She completed her Bachelor of Pharmacy in Teegala Ram Reddy College of Pharmacy, Hyderabad in 2016. Her research interest is the development of Bioanalytical method, applying the method for the determination of the pharmacokinetic parameters and investigating the pharmacokinetics drug-drug interaction.

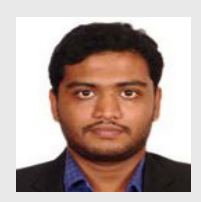

Amit Kumar Sahu is a Ph.D research scholar in the Department of Pharmaceutical Analysis, National Institute of Pharmaceutical Education and Research (NIPER) -Ahmedabad, India. He obtained his master degree in Pharmaceutical Analysis from National Institute of Pharmaceutical Education and Research (NIPER)- Hyderabad, India in 2017. His area of research includes forced degradation studies, metabolite profiling, and pharmacokinetic interaction studies. He has sound knowledge in the development and validation of stability indicating assay method, characterization of degradation products and bioanalytical method development and validation.
\end{abstract}




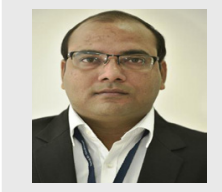

Manish Kumar Sharma is a Ph.D. research scholar in the Department of Pharmaceutical Analysis, National Institute of Pharmaceutical Education and Research (NIPER)-Ahmedabad, India. He has done his master degree in Pharmaceutical Analysis from Institute of Pharmacy, Nirma University, Ahmedabad, Gujarat India in 2011. Manish Sharma has 2.5 year experience in pharmaceutical industry related to regulatory affairs as well as 1.5 year experience in Anti-Doping analytical Science. His research area interest identification and characterization of Degradation products, Metabolite profiling and pharmacokinetic studies in different biological samples.

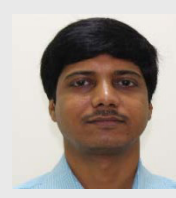

Dr. Pinaki Sengupta is a faculty member of the Department of Pharmaceutical Analysis, National Institute of Pharmaceutical Education and Research (NIPER)- Ahmedabad, India. He is a Ph.D in Pharmacy from Jadavpur University, India. Dr. Pinaki has more than ten years of experience in academic and industry-based research. He has published more than fifty articles in various high impact international journals. He is serving as the Editorial Board Member of various scientific journals. His work has been cited more than 950 times in scientific articles.

Cite this article: Reddy PA, Sahu AK, Sharma MK, Sengupta P. Development and Validation of a Simultaneous Bioanalytical Method for Methotrexate, Sulfasalazine and Hydroxychloroquine in Rat Plasma following Single Step Protein Precipitation Technique. Indian J of Pharmaceutical Education and Research. 2020;54(2s):s358-s367. 